\title{
Medición y cartografía del impacto socialmente percibido ante industrias contaminantes con un estimador de densidad núcleo (kernel) y SIG: aplicación al caso del complejo industrial Ventanas, Chile*
}

\section{Measurement and mapping of socially perceived impact related to pollutant industries using a kernel density estimator and GIS. The case study of Ventanas industrial site (Chile)}

\author{
Antonio Moreno Jiménez ${ }^{1}$ y Manuel Fuenzalida Díaz ${ }^{2}$
}

\section{RESUMEN}

Los efectos ambientales derivados de actividades humanas ocasionan los llamados campos de externalidades en el entorno de ellas, manifestándose bien como emisiones

\footnotetext{
* Trabajo realizado en el marco de los proyectos CSO2011-26177 "Contaminación atmosférica urbana y justicia ambiental: metodología de evaluación y estudio de casos con sistemas de información geográfica" y "Polución del aire, poblaciones vulnerables y salud: análisis de injusticias ambientales basados en geotecnologías", CSO2014-55535-R, financiados por el Ministerio de Economía y Competitividad de España.

Una versión preliminar y breve de este trabajo fue presentada en 2013 en la XIV CONFIBSIG, Honduras.

Los autores expresan su agradecimiento a los dos evaluadores anónimos por sus valiosas críticas.

${ }^{1}$ Departamento de Geografía, Universidad Autónoma de Madrid, Cantoblanco, 28049-Madrid, España, antonio.moreno@uam.es. ORCID iD: http://orcid.org/0000-0001-6687-1448.

2 Departamento de Geografía, Universidad Alberto Hurtado, Santiago, Chile, mfuenzal@uahurtado.cl. ORCID iD: http://orcid.org/0000-0003-3207-5763.
} 
o impactos físicos, bien como vivencias negativas afectando a la población. La medición de ese malestar social y su expresión espacial constituye el asunto central de esta contribución, en la que se aborda el caso de los residentes próximos a un gran complejo industrial en Chile. A tal fin se diseñó y realizó una encuesta domiciliaria para determinar la percepción de varios impactos ambientales, que luego fue georreferenciada. Para establecer la magnitud del malestar socio-espacial se recurrió a la técnica de los estimadores de densidad núcleo (kernel), que permiten generar con SIG superficies y expresivos mapas representativos de las diversas experiencias negativas, así como un indicador sintético de las mismas. Con ello se pretende aportar una vía nueva para aprehender, en cantidad y en lugar, esos elusivos efectos, aplicable en labores como la evaluación de impactos ambientales.

Palabras Clave: estimador de densidad kernel; mapas de externalidades; impacto socio-ambiental; percepción ambiental; contaminación industrial.

\begin{abstract}
The environmental effects of human activities shape the so-called externality fields around them, portrayed either as immissions and physical impacts, or as negative experiences affecting population. The measurement of this social "bad-being" and its spatial expression is the main issue of this contribution, where the case of residents near a large industrial complex in Chile is tackled. To this end a home survey, lately geo-referenced, was designed and achieved to determine the perception of various environmental impacts. To elucidate the amount of socio-spatial "bad-being" a kernel density estimator was applied, provided it enables to obtain GIS based surfaces and expressive maps representing the various negative experiences, and a synthetic index of them too. In this way it is intended to provide a new way to capture, both in quantity and place, these elusive effects, which might be applicable in environmental impact assessment.

KEY- WORDS: kernel density estimator; externality maps; socio-environmental impact; environmental perception; industrial pollution.

Cómo citar este artículo / Citation: Moreno Jiménez, Antonio y Fuenzalida Díaz, Manuel (2017): "Medición y cartografía del impacto socialmente percibido ante industrias contaminantes con un estimador de densidad núcleo (kernel) y SIG: aplicación al caso del complejo industrial Ventanas, Chile", Estudios Geográficos, LXXVIII/282, pp. 225-256.
\end{abstract}

\title{
1. INTRODUCCIÓN
}

La calidad ambiental constituye una preocupación prioritaria por cuanto con frecuencia provoca consecuencias de gran trascendencia social, económica, política, etc. Baste recordar que binomios como salud-enfermedad, bie- 
nestar-malestar, sufrimiento-felicidad, estigma-prestigio (imagen y marca territorial), atracción-repulsión entre actividades, etc. se vinculan a la calidaddegradación del entorno. Una de las facetas de mayor interés de esa calidad tiene que ver con los efectos o impactos de carácter ambiental que fenómenos o procesos (naturales o antrópicos) ocasionan sobre la población. Su conocimiento constituye una necesidad principal, puesto que permite desvelar su trascendencia y plantear acciones. La multiplicidad de los tipos de efectos derivados (a menudo asimilables a externalidades espaciales) ha llevado a adoptar perspectivas analíticas e instrumentos de medición muy diversos. Así, junto a indicadores de tipo objetivo (e. g. basados en medidas instrumentales o estadísticas), el recurso a otros de naturaleza subjetiva (i.e. basados en la percepción o sensación humana) resulta habitual.

La evaluación de aspectos ambientales a partir de las percepciones humanas conforma una vía apropiada para aproximarse al grado de bienestar o malestar sentido y a su geografía. En ese sentido los estímulos provenientes del entorno al ser captados, identificados y valorados por los ciudadanos, posibilitan la determinación de los conocidos campos de impactos o de externalidades que emergen alrededor de los focos emisores, sea cual sea su naturaleza (Pinch, 1985; Moreno y Escolano, 1992: 214-218). Ello abrió la puerta a una cartografía y análisis espacial de esas apreciaciones sociales sobre hechos ambientales y, por extensión, a una determinación de perjuicios o costes, a veces soslayados $\mathrm{u}$ ocultados. Cuando se trata de externalidades generadas por actividades humanas, por ejemplo las productivas, su evaluación desde la subjetividad personal y su localización espacial es la condición necesaria para poder dar respuestas fundadas sobre los componentes del malestar ocasionado (costes externos) y la forma como se reparten social y espacialmente. Es factible así desvelar quién, cómo, cuánto y dónde se ve afectado, pudiéndose avistar, como novedosa utilidad, a modo de una «contabilidad» espacializada y representativa del malestar de la población expuesta a la degradación ambiental. En la sociedad actual, la comunicación visual de los impactos sentidos por los ciudadanos a los agentes sociales y responsables públicos y empresariales, mediante cartografías muy detalladas espacialmente, es clave para forjar juicios de valor y estimular un manejo preventivo de conflictos potenciales y posibles decisiones correctivas o paliativas.

Conviene recordar que el abordaje de la percepción ambiental, como describen Catalán-Vázquez y Jarillo-Soto (2010) para el caso de la contaminación atmosférica, ha sido realizado desde planteamientos paradigmáticos muy diferentes (positivistas, teoría crítica, constructivistas), que resultan complementarios en sus logros. El presente trabajo trata de profundizar en ese frente de 
indagación, ya de notable recorrido, proponiendo un procedimiento singular para la medición y plasmación espacial de los efectos ambientales percibidos por los residentes próximos a un gran complejo industrial, que se aplica a un caso de Chile. A tal fin se adopta la aproximación o paradigma calificado como geotecnológico (Buzai, 2011a; Moreno, 2010, 2013), el cual resulta especialmente idóneo para el problema.

Procede advertir que el alcance del estudio se ciñe a la faceta de diagnóstico o evaluación y no contempla la explicación de dichas percepciones, que se abordará en fases ulteriores de la investigación; se busca así plantear y difundir una vía nueva para aprehender ciertos impactos socio-ambientales derivados de actividades humanas, que resultan algo elusivos de cuantificar y patentizar, pero que habrían de ser muy tenidos en cuenta en la organización del territorio, pues conciernen a principios fundamentales del desarrollo, tales como el bienestar, la sostenibilidad o la justicia ambiental. Es pertinente añadir, por otra parte, que nuestra aproximación difiere claramente del enfoque centrado en la estimación a priori de zonas potencialmente sometidas a amenazas tecnológicas (Propeck-Zimmermann et al., 2009), pues nuestro análisis parte de la experiencia de las personas, es decir, intenta desvelar la magnitud de los efectos sentidos a posteriori, averiguando cuántos ciudadanos residentes en ámbitos con degradación ambiental de origen industrial, perciben ciertos impactos negativos en su micro-entorno residencial (el dónde); se trata pues de aproximarse a un ensayo de «contabilidad», a la vez social y espacial, del malestar percibido.

En el siguiente apartado se presentan las bases conceptuales y los antecedentes de investigación más significativos, como contexto para explicitar los objetivos; luego se exponen las fuentes de información y los métodos adoptados, en los que el recurso a técnicas de análisis espacial y a la tecnología SIG proporciona la base fundamental. Seguidamente se describen algunos de los hallazgos alcanzados y se termina con una discusión de los mismos y las conclusiones.

\section{Contexto teórico y ANTECEDENTES DE ESTUdio}

Es tradicional en las investigaciones geográficas considerar que la mente humana genera imágenes subjetivas del medio, que terminan teniendo gran importancia en el comportamiento espacial de los individuos (Gould y White, 1974). Estas imágenes son producto de la sensación inmediata y del recuerdo de experiencias anteriores, que las personas utilizan para interpretar la infor- 
mación proveniente del medio exterior y orientar su acción. Según Lynch (1960), esta imagen mental no sólo es una forma de comprender el espacio para lograr una orientación del mismo, sino que también se asocia a sentimientos y emociones vinculadas al espacio vivido, de allí la importancia que tiene cada lugar para el sujeto.

La Geografía cuenta con herramientas para tratar esta cuestión: el mapa mental, que es una representación subjetiva del ambiente. Partiendo de varios autores que han incursionado en este tema Buzai (2011b) clasifica los mapas mentales según que estén basados en elementos visuales (Lynch, 1960), en preferencias (Gould, 1975) o en comparaciones (Castro, 2004). De ellos, es de interés aquí mencionar los basados en preferencias en los que Gould (1974) establece seis líneas diferentes de abordaje para el estudio de la percepción y la valoración ambiental: (1) percepción de recursos, (2) percepción de paisajes, (3) percepción del riesgo, (4) percepción del espacio, (5) percepción del ambiente urbano y (6) percepción como evaluación ambiental. En este último se estudia de qué manera la población tiende a aprehender y evaluar diferentes sectores del espacio geográfico, cuyo tratamiento con técnicas utilizadas por la geografía cuantitativa (i.e. cuadrados / cuadrantes, densidad núcleo o ker$n e l$, interpolación) permite crear y analizar superficies de percepción, que están llamadas a convertirse en importantes instrumentos para la toma de decisiones.

En esa línea, se le atribuye utilidad al mapa mental principalmente en tres aspectos (Catling, 1978):

- conforma un instrumento de diagnóstico, ya que es una manifestación del nivel de desarrollo espacial;

- es una fuente de información, puesto que permite conocer los diversos elementos significativos en las imágenes mentales, y

- se considera un producto de instrucción, debido a que orienta y aporta indicaciones para la creación cartográfica.

La expresión de percepción ambiental, central para este trabajo, encierra diferentes acepciones dependiendo de la disciplina dominante (e. g. Psicología, Sociología, Geografía, etc.) a la que se adscribe el investigador, puesto que se trata de un nicho de trabajo multidisciplinar. A los efectos de esta investigación, enraizada en la Geografía, resulta pertinente recordar las cuatro facetas relevantes en la percepción ambiental distinguidas por Barroto et al. (2011):

1. Visión del medio ambiente y de los problemas ambientales: Ideas del individuo sobre el medio ambiente y sus dimensiones, además de los problemas ambientales y su extensión. 
2. Responsabilidad ambiental: Apreciación de los individuos sobre los agentes causantes de problemas ambientales y aquellos agentes que deben intervenir para evitarlos.

3. Actitud ambiental y decisión de incorporarse al cambio: Predisposición del pensamiento humano a actuar en favor o en contra del entorno social, teniendo en consideración sus vivencias, experiencias, conocimientos y valores con respecto a su entorno.

4. Formación medioambiental: Impresión que tienen los individuos sobre la calidad y efectividad de las acciones de educación ambiental.

La percepción ambiental se puede considerar, pues, como una base sustancial para las decisiones de manejo y conservación del medio natural, pero al mismo tiempo puede contribuir al diseño de políticas públicas orientadas a redirigir los procesos de deterioro ambiental.

De cara a la evaluación ambiental en términos de percepción de peligros o emisiones de actividades o focos (e. g. contaminantes) resulta imprescindible incorporar el concepto de bienestar, aunque como señala Moreno (1998), la geografía del bienestar resulta, a menudo, inseparable de la del malestar. La atención al tema atraviesa las fronteras disciplinares y así en la ciencia política, economía regional, geografía, psicología, derecho, ciencias de la gestión, medio ambiente, etc. está aumentando la cifra de publicaciones sobre el mismo; en ellas se han popularizado acrónimos tales como LULU (locally unwanted land uses), NIMBY (not in my back yard) o NIABY (not in anybody back yard) para referirse a esos síndromes o conflictos socio-políticos bien conocidos que están ligados a la calidad-deterioro ambiental.

La parcela concreta del análisis de las percepciones ciudadanas de actividades molestas, insalubres y peligrosas, catástrofes o riesgos, y su correlato en el bienestar o malestar, cuenta con una tradición importante en Geografía (vid. Golledge y Stimpson, 1997) y en Psicología Ambiental (Jiménez Burillo y Aragonés, 1991; Valera et al., s.f.). Dedicaremos un poco de atención a examinar estudios sobre esa parcela, por resultar pertinentes a nuestros fines aquí.

En la disciplina psicológica se ha adoptado ampliamente el llamado paradigma psicométrico, sustentado en el uso del análisis factorial, para determinar factores explicativos de tales percepciones (Siegrist et al., 2005). Entre dichos condicionantes los sociales, demográficos, culturales, religiosos, etc. han sido objeto de atención en trabajos como los de Fischhoff et al. (1978), Gutteling y Wiegman (1993), Kleinhesselink y Rosa (1991), Keown (1989), Lai y Tao (2003). La tesis de los determinantes culturales de la percepción de los riesgos ambientales ha sido comprobada también mediante métodos no cuantitativos, tales como las entrevistas en profundidad, por ejemplo por Bax- 
ter y Greenlaw (2005). Bickerstaff et al. (2004) presentaron una revista de trabajos sobre percepción de riesgos, revelando la convergencia en los hallazgos de muchos trabajos sobre tales factores socioculturales.

Las facetas espaciales de la percepción de amenazas y problemas ambientales han sido examinadas por autores diversos y con fines distintos. Shippee et al. (1980: 35-36) han aportado algunos hallazgos destacados y un tanto sorprendentes, tales como que en las zonas de alto riesgo a) se niegue la condición de amenazante del entorno, y b) se subestime la probabilidad de futuras calamidades o desastres. Así mismo, en zonas más distantes a un accidente reciente crece esa percepción de peligro. Esta última constatación concuerda con una «teoría de disonancia cognitiva» reportada en la bibliografía, según la cual en zonas próximas a un accidente reciente se tiende a minimizar el peligro presente y futuro del mismo, en tanto que en zonas más distantes esa percepción de peligro aumenta.

Stefanko y Horowitz (1989) investigaron a residentes en torno a un depósito de residuos tóxicos en el sur de California, hallando que los residentes cercanos al depósito desarrollaban creencias negativas significativamente altas; junto a ellos los más expuestos visual u olfativamente al depósito se sentían más amenazados y expresaban que su calidad de vida estaba deteriorada. Los residentes de bajo nivel educativo, los padres con niños, los arrendatarios y los residentes recientes en la zona ( $<2$ años) también mostraban cifras superiores de sentimientos negativos. Con la edad la sensación negativa tendía a disminuir. Brody et al. (2004) usando SIG y técnicas cuantitativas, no hallaron correlación significativa entre la percepción de la calidad del aire y los datos medidos sobre polución, pero sí parecía influida por otras variables geográficas y socio-demográficas (edad, raza e identificación política).

Un relevante asunto, la propia verosimilitud de los datos de percepción ha sido cuestionada en algún estudio como el de Arteaga y Pasquali (2013) cuando investigaron los niveles de percepción social por parte de la población de localidades cercanas a empresas cárnicas en una zona de Venezuela, desvelando la existencia de falsas creencias entre la población respecto a los posibles impactos ambientales que estarían produciendo estas empresas (a las que erróneamente se les imputaban).

Ciertos autores han ampliado horizontes examinando, por ejemplo, el efecto de la percepción de los peligros ambientales sobre los valores de los inmuebles residenciales. Así, Zhang et al. (2010) señalan al respecto hallazgos inconsistentes en la bibliografía y de su propio trabajo solo llegan a colegir que la percepción del riesgo es un factor mediador parcial entre la proximidad al peligro y el valor del inmueble. 
Desde posiciones científicas genuinamente geográficas, y por tanto más cercanas al objeto de este artículo, los abundantes trabajos que han abordado las externalidades espaciales asociadas a actividades de servicios tales como hospitales psiquiátricos (Dear et al., 1980), campos de fútbol (Mason y Robins, 1991; Mason y Moncrieff, 1993), centros de atención a drogodependientes (Moreno, 1992, 1998), auditorios de conciertos al aire libre (Chase y Healey, 1995) y parques públicos (Pérez-Tejera, 2012) suponen un innegable referente para nuestro estudio. Ello concierne, tanto al procedimiento de obtención de datos, encuestas para determinar la percepción y actitudes hacia esas dotaciones y los problemas o efectos ambientales que generan (e.g. tipo, intensidad, duración, etc.) mediante escalas ordinales (e.g. Bale, 1981; Schroeder, 1984), como a la finalidad de plasmar cartográficamente los denominados como campos de externalidades espaciales.

Para actividades industriales, merecen reseñarse varias contribuciones. Ford et al. (2007) acometieron un estudio para evaluar el entorno de las escuelas, cartografiando los lugares (puntos) y recorridos evaluados por los niños encuestados, lo que permitió aprehender diversos atributos percibidos de ese entorno. Sofer et al. (2012), por su parte, han descrito el impacto en la calidad de vida de la población cercana a pequeñas industrias y talleres, producto de molestias por ruido, emisiones al aire y contaminación del suelo.

Los trabajos de Bonnet et al. $(2012,2014)$ han acometido la identificación de zonas de riesgo industrial por parte de los residentes en el estuario del río Sena (Francia) mediante una metodología mixta combinando componentes cualitativos (mapas mentales de las zonas donde el encuestado considera que hay riesgo) y cuantitativos (geolocalización y superposición de los croquisrespuesta con SIG).

Glatron y Beck (2008) han analizado la vulnerabilidad socioespacial y la percepción de riesgos en la ciudad francesa de Mulhouse, siendo destacable su construcción de un índice de vulnerabilidad de la población por distritos (Glatron y Beck, 2005), uno de cuyos componentes es la percepción de diversos tipos de riesgos (naturales y tecnológicos), lo que permitía una cartografía agregada. Entre sus resultados merece reseñarse la constatación de que la población cercana a industrias peligrosas aparecía menos consciente del riesgo industrial, lo que avalaría la teoría de disonancia cognitiva reportada antes.

Procede referir finalmente que las indagaciones específicas sobre percepción de la polución aérea — una amenaza notable y elusiva - son también abundantes, como se evidencia en la revisión de Catalán-Vázquez y JarilloSoto (2010). En ellas se han documentado hallazgos valiosos para interpretar 
esa percepción y explicar sus relaciones con otras variables socioeconómicas, funcionales o espaciales.

Como balance de las indagaciones últimas comentadas sobre percepción de amenazas, externalidades o consecuencias cabe señalar que, metodológicamente, en muchos casos se ha tratado de establecer qué zonas soportarían más o menos impacto, usando para ello calificaciones emitidas por los encuestados sobre los lugares (respuestas sobre la intensidad, en escala ordinal). Los mapas, cuando los hay, son, pues, una síntesis de la apreciación del nivel del impacto, subjetivamente estimado, sobre cada parte del territorio (vías, zonas, etc.), aportando un valor informativo inequívoco. Sin embargo, dejando al margen aquellos trabajos que investigan asociaciones de esas percepciones con otros fenómenos relacionados (con fines explicativos), poco se ha profundizado en una cuestión: cuánta gente siente un tipo de impacto dado en el micro-entorno donde vive. Tal es, sin embargo, la prioridad de este trabajo, que se inspira en el método ensayado por Moreno (1992 y 1998), buscando medir y visualizar el descontento social provocado por varias externalidades ambientales y mostrándolo como una «topografía» con alta resolución espacial.

Esta contribución, por tanto, aspira a mostrar aspectos diferenciados y notables de la geografía de los perjuicios percibidos e imputados subjetivamente a una actividad industrial cercana, avistando tres objetivos complementarios:

- Experimentar una metodología geográfica que permite medir y representar la cuantía del malestar social, mediante mapas novedosos y a escala detallada, exhibiendo dónde y cuánta población siente ciertos efectos negativos.

- Caracterizar los patrones espaciales del malestar socio-ambiental inherente a entornos contaminados, desagregando por tipos de efectos distintos.

- Ensayar la elaboración de mapas sintéticos de multiafección percibida, a partir de los patrones parciales, que expresen la magnitud acumulada del malestar de los residentes.

Con ello se persigue ilustrar y difundir un procedimiento de «contabilidad socio-espacial» que enriquezca los diagnósticos de los impactos de actividades humanas, centrado específicamente en la dimensión subjetiva de dichos efectos, y más concretamente en las molestias de los ciudadanos. La visualización cartográfica de dichas percepciones, en tanto que externalidades espaciales elusivas, pero reales y medibles, facilitará su interpretación y una valoración más exacta por parte de los agentes sociales y de los decisores públicos y privados; ello abriría la puerta a su proyección en las labores de planificación y monitoreo territorial. 


\section{Zona de Estudio, Materiales y mÉtodos}

\section{Localización del área de estudio}

El ámbito elegido se sitúa en el borde costero de dos municipios de la parte central de Chile: Quintero y Puchuncaví (región de Valparaíso). El Decreto Supremo N³46 del Ministerio de Agricultura chileno del año 1993 declara que la zona saturada por anhídrido sulfuroso $\left(\mathrm{SO}_{2}\right)$ y material particulado respirable $\left(\mathrm{MP}_{10}\right)$ es aquella circundante al gran Complejo Industrial Ventanas, que se ubica jurisdiccionalmente en las comunas de Quintero y Puchuncaví. Entre las coordenadas UTM Zona 19 H: 6387381,3 - 6370657,6 Norte y 262413,3 - 286472,9 Este.

Los límites que se establecen en el Decreto son los siguientes:

- Norte: desde el Océano Pacífico hasta la desembocadura del Estero Catapilco, y siguiendo éste hasta su confluencia con el Estero La Canela.

- Sur: desde la cumbre del Cerro Colorado, bajando en línea recta hasta la intersección del Canal Mauco con el Estero Mantagua.

- Este: desde la cumbre Cerro Alto del Agua del Peumo, siguiendo por la divisoria de aguas hasta el cerro Pucalán, continuando en línea recta hasta la cumbre del Cerro Piedra Trepada.

- Oeste: línea de costa del Océano Pacífico, desde la desembocadura del Estero Mantagua por el sur, hasta la desembocadura del estero Catapilco por el Norte.

La superficie es de $402,36 \mathrm{~km}^{2}$ y administrativamente limita con las comunas de Nogales al Este, Concón al Sur, Zapallar al Norte y con el Océano Pacífico al Oeste. Para este caso, el área de estudio se ha acotado a los centros poblados que se ubican al interior de las citadas comunas: Quintero, Loncura, Ventanas, La Greda, La Chocota, Horcón y Puchuncaví (véase figura 1). En ella se observa la existencia de varios asentamientos, ubicados a distinta distancia (desde los adyacentes hasta los sitos a unos $7 \mathrm{~km}$ aproximadamente) y orientación respecto al complejo industrial, y conteniendo cifras de población diferentes. Ello les expone a los efectos ambientales externos de las fábricas de una manera clara. 


\section{FIGURA 1}

LA ZONA DE ESTUDIO, SITA ENTRE LAS COMUNAS DE QUINTERO Y PUCHUNCAVÍ, REGIÓN DE VALPARAÍSO, CHILE

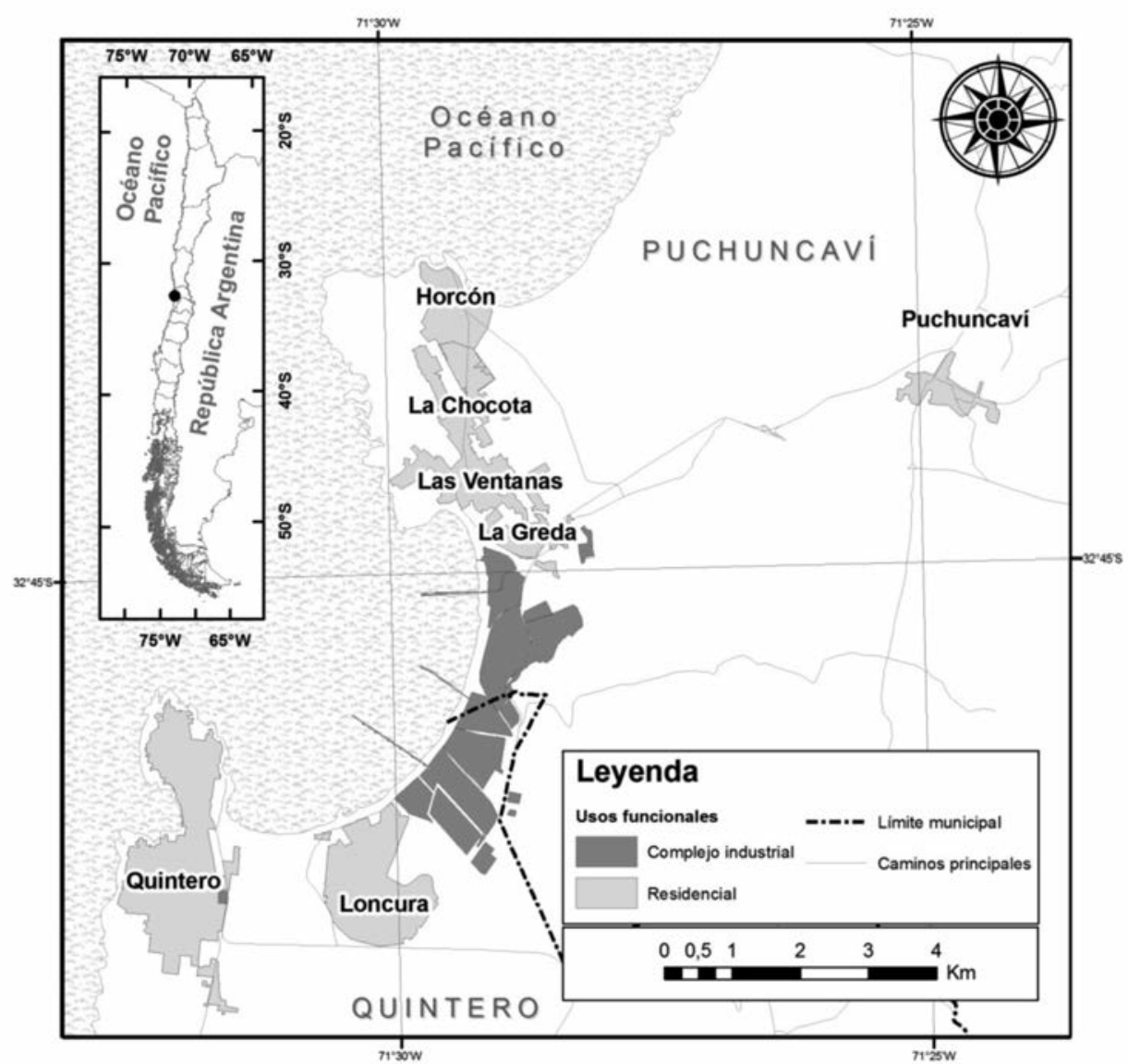

\section{Fuentes de información}

Encuestas a la población residente

El objetivo de la aplicación del instrumento fue evaluar la percepción de los efectos ambientales sobre la población y el territorio, considerando el nivel de intensidad global y la variabilidad temporal de las molestias sentidas en un 
período dado (el último año) por el encuestado y por otros miembros del hogar, debido a la polución industrial. La selección de los encuestados se basó en un muestreo espacial sistemático, considerando como universo a un representante por vivienda. La selección de las viviendas se sustentó en recorridos exhaustivos de todos los frentes de manzana con viviendas en la zona asignada a cada encuestador. Los equipos de trabajo de campo se desplegaron en las siguientes unidades territoriales: Quintero, Loncura, La Greda, Ventanas, La Chocota, Horcón y Puchuncaví, obteniéndose 290 encuestas para todo el ámbito en estudio. La encuesta se realizó mediante entrevistas domiciliarias durante el mes de marzo de 2012. En ellas se requirió a los encuestados pronunciarse acerca de si en el último año habían percibido ciertos tipos de efectos (malos olores, ruidos, polución atmosférica, etc.) procedentes del complejo industrial, su intensidad y frecuencia (aunque estos dos últimos aspectos no serán analizados aquí, por limitaciones de espacio).

\section{Otras fuentes}

Junto a los datos de la encuesta se ha utilizado cartografía digital sobre los asentamientos, límites municipales, red viaria, etc. procedente del Sistema Integrado de Información Territorial (SIIT) de la Biblioteca del Congreso Nacional de Chile.

\section{Técnicas de análisis}

Puesto que los efectivos de la muestra en cada asentamiento son aproximadamente proporcionales a la población, la teoría del muestreo permite asumir una aceptable representatividad de la misma en su cuantía total y en las respuestas, lo que equivale a decir, a su percepción de los problemas ambientales. A la hora, por tanto, de analizar espacialmente los resultados es sostenible adscribir tales respuestas al domicilio de los encuestados y así se hizo al georreferenciar los datos de la encuesta. En principio, cabe pensar en varias alternativas para representar cartográficamente $\mathrm{y}$ analizar las respuestas cualitativas sobre la percepción individual de los efectos molestos. Tras algunos ensayos, pareció más prometedor adoptar el planteamiento y técnica utilizados por Moreno (1992 y 1998).

En síntesis, se parte de asumir una clasificación previa de las respuestas a cada pregunta y retener particularmente las que afirman la percepción de mo- 
lestias, por cuanto son expresión del malestar asociado a una externalidad concreta. La trascripción espacial y visualización de dichas respuestas bien podría recurrir a una cartografía de símbolos puntuales bajo el modelo vectorial de los SIG, pero para una representación más realista de la espacialidad humana y una mejor aprehensión de los resultados, pareció más acertado recurrir a un estimador de densidad focal núcleo o kernel y elaborar mapas bajo el modelo raster. Su aplicación implica asumir, de acuerdo con la lógica de tales estimadores ${ }^{3}$, que el dato puntual en cuestión se despliega por un entorno alrededor de la vivienda, de tamaño dado por la «anchura de la ventana» (bandwidth o search radius) del kernel. Ello resulta congruente con un entendimiento de la espacialidad del individuo, que aunque centrada en su domicilio, en su movilidad espacio-temporal habitual se desenvuelve por el entorno del mismo y probablemente con una frecuencia (densidad) decreciente desde el punto-domicilio hasta una distancia razonable (definida por la anchura de la ventana). Se trataría de un subconjunto del concepto de «campo de actividad espacial» del individuo, calificable como «entorno personal próximo» (EPP) en el que la persona desarrolla actividades cotidianas varias, centradas y factibles desde el punto-domicilio con un esfuerzo / coste casi irrelevante. Si se consideran las denominaciones tradicionales dentro del espacio residencial, una aproximación a ese ámbito sería el de barrio como lugar de vivencia.

A efectos de nuestro análisis pareció razonable fijar ese parámetro en 500 $\mathrm{m}$, teniendo en cuenta que la distancia media de cada punto al vecino más próximo es bastante menor, 125,1 m. Ello permitiría la emersión de una superficie de densidad focal ni demasiado suavizada, ni excesivamente detallada (rugosa). Esa importante decisión implica: 1) que se asume un campo de actividad en torno al domicilio de hasta $1 \mathrm{~km}$ de diámetro como máximo (78,5 ha); y 2) que se realiza un reparto del peso unitario de cada respuesta afirmativa en un círculo de ese tamaño (como densidades), aunque de manera desigual según la lógica del kernel: más intenso en la parte central y más somero en la periferia del círculo. Según este planteamiento, se obtendrán en la capas raster derivadas de cada pregunta píxeles con mayor densidad allí donde se concentran las respuestas afirmativas y con menor densidad donde hay pocas de tales respuestas. El resultado sería, por tanto, una plasmación cuantitativa del malestar socio-ambiental sentido, desvelada espacialmente a través de la muestra. Ahora puede comprenderse la importancia de lograr en el muestreo una distribución espacial de la muestra bien representativa ( $v$.gr. con un proce-

${ }^{3}$ Una presentación de tales estimadores puede verse en diversas obras, por ejemplo, Moreno (1991), Santos Preciado y García Lázaro (2008: 267-312). 
dimiento sistemático, como aquí se hizo). Un sesgo en ello implicaría la invalidez (por ese defecto) del tratamiento analítico que hemos descrito. Procede añadir que el tamaño del píxel adoptado es de $50 \mathrm{~m}$, con el criterio de obtener capas raster sin la perturbación visual del pixelado.

Las capas de densidad en cuestión se representan con una paleta monocroma consistente sin intervalos, para evitar la rigidez asociada a ellos. Se adopta pues una gradación continua de color en correspondencia lineal con la amplitud de los datos, mediante lo que se conoce como expansión lineal del contraste o linear stretch (Minimum-Maximum). Ahora bien, dado que la amplitud de las densidades de cada capa suele diferir, pues el valor máximo depende de la frecuencia y ubicación de las respuestas afirmativas a cada pregunta, se ha evitado la inconsistencia entre capas adoptando (forzando) una amplitud constante para la paleta de color: la de la capa de densidades de la muestra total de encuestados, que representaría la situación de densidad máxima (por incluir a la totalidad de los $\mathrm{n}$ residentes encuestados). Ello implicará que, a menudo, en los mapas de cada uno de los efectos percibidos, la totalidad de la paleta cromática no llegue a mostrarse; en particular, los tonos más intensos asignados a los valores altos probablemente no aparecerán. Esto, en lugar de ser un inconveniente, resulta una ventaja, pues asegura la comparabilidad de los mapas, mediante una «normalización» de la paleta, que hace innecesaria la normalización de los datos de densidad a los efectos de percepción visual.

Adicionalmente, y puesto que la gradación continua de color no propicia una aprehensión sintética y simple, se ha introducido otro componente cartográfico: las isolíneas a intervalos regulares de 0,1 encuestados / ha, las cuales permiten resaltar con nitidez las zonas donde se concentran los encuestados que reconocen una molestia ambiental concreta. Su gradación también en grosor y las etiquetas cuantitativas con los valores de iso-molestias completan las ayudas a la apreciación.

Los tratamientos han sido desarrollados mediante ArcGIS, programa en el que se halla disponible la denominada función cuadrática de densidad de probabilidad núcleo (kernel). Para un lugar (píxel) dado, s, (vid. Silverman, 1986: 76 , ecuaciones 4.1 y 4.5 ) se puede expresar como:

$$
f^{\prime}(s)=\frac{1}{n h^{2}} \sum_{i \mid d_{i} \leq h}^{n} \frac{3}{\pi}\left(1-\frac{d_{i}^{2}}{h^{2}}\right)^{2}
$$

Siendo $\mathrm{d}_{\mathrm{i}}=$ la distancia entre el punto-dato i y el lugar $\mathrm{s}, \mathrm{h}=$ radio de la ventana de búsqueda y $\mathrm{n}=$ el número de puntos-dato en la zona de estudio. 
Como información comparativa relevante se presentarán también los estadísticos descriptivos básicos de cada capa. Con objeto de disponer de una visión sintética de los efectos negativos percibidos se ha construido además un índice sencillo que trata de resumir los resultados de las cinco preguntas analizadas según una lógica aditiva. A tal fin, para cada encuestado se obtuvo la proporción del número de respuestas afirmativas respecto al número de efectos considerados (cinco) y sobre tal valor fue aplicado el estimador kernel. Puesto que los análisis individuales para cada uno de los efectos negativos se sustentaban en valores 0/1 (se percibe/no se percibe), el uso de esa proporción para cada encuestado georreferenciado mantiene la consistencia en amplitud de los datos (entre 0 y 1) y, por ende, la comparabilidad entre los resultados.

\section{ANÁliSIS DE RESULTADOS}

\section{La distribución por localidades de la muestra y de los problemas ambientales percibidos}

Antes de analizar los patrones de densidad de la afección ambiental sentida conviene presentar sucintamente la distribución espacial de la muestra y de las respuestas generales para una adecuada contextualización de las mismas.

En el cuadro 1 se constata que, en el conjunto del área de estudio, la percepción de impactos negativos imputados al complejo industrial es notable, pues en cuatro de los tipos de afección investigados los porcentajes exceden de 50. Por este orden destacan la contaminación del aire, que es muy altamente sentida $(76,90 \%)$, seguida de los olores $(61,72 \%)$. La suciedad en viviendas y el ruido se sitúan a continuación con frecuencias ligeramente superiores a la mitad de la muestra y finalmente la conciencia de problemas de salud es algo menos referida (39,31\%). Aunque tentativamente, cabría interpretar estos datos como una manifestación de la prevalencia de las sensaciones visuales (humos y suciedad), olfativas y auditivas, por este orden, en tanto que los efectos sobre la salud, aunque pudiesen ser más lesivos, quedan bastante rezagados en la percepción social, quizá por la dificultad de establecer subjetivamente la conexión causal con las emisiones industriales. En cualquier caso, lo relevante es que los niveles de conciencia individual de los problemas son amplios. El cálculo con el sistema estadístico NCSS 9 (Hintze, 2013) de los límites de confianza exactos (basados en la distribución binomial) para un nivel del 95\% ( $\alpha=0,05)$ permite aseverar que, tomando - conservadoramente- el límite inferior, los porcentajes de afectados siempre son más de una tercera parte y en cuatro de los impactos superarían el 45\%. 
CuAdro 1

PROBLEMAS PERCIBIDOS EN EL CONJUNTO DEL ÁREA DE ESTUDIO

\begin{tabular}{l|c|c|c|c}
\hline & \multicolumn{2}{|c|}{ Respuesta "Sí" } & \multicolumn{2}{c}{ Límites de confianza $(\alpha=0,05)$} \\
\hline \multicolumn{1}{c|}{ TIPO DE AFECCIÓN } & Frec. & $\%$ & Inferior & Superior \\
\hline Olor & 179 & 61.72 & 55.86 & 67.35 \\
\hline Ruido & 153 & 52.76 & 46.84 & 58.62 \\
\hline Contaminación del aire & 223 & 76.90 & 71.61 & 81.62 \\
\hline Problemas de salud & 114 & 39.31 & 33.65 & 45.19 \\
\hline Suciedad en vivienda & 159 & 54.83 & 48.90 & 60.65 \\
\hline$N^{o}$ de encuestados & 290 & 100.00 & & \\
\hline
\end{tabular}

Fuente: encuesta propia.

\section{CUADRO 2}

DISTRIBUCIÓN POR LOCALIDADES DE LA MUESTRA Y DE LA AFECCIÓN PERCIBIDA POR LOS ENCUESTADOS

\begin{tabular}{l|r|r|r|r|r|r|r|r|r|r}
\hline \multicolumn{1}{c|}{ LOCALIDADES } & Total & \multicolumn{1}{c|}{$\%$} & Quintero & $\%$ & Loncura & $\%$ & $\begin{array}{c}\text { Horcón - } \\
\text { Las Ventanas } \\
\text { - La Greda }\end{array}$ & $\%$ & Puchuncaví & $\%$ \\
\hline $\mathrm{N}^{\text {o } \text { Encuestados }}$ & 290 & 100 & 72 & 24.83 & 47 & 16.21 & 117 & 40.34 & 54 & 18.62 \\
\hline TIPO DE AFECCIÓN & SI (frec.) & $\%$ & SI (frec.) & $\%$ & SI (frec.) & $\%$ & SI (frec.) & $\%$ & SI (frec.) & $\%$ \\
\hline Olor & 179 & 100 & 40 & 22.35 & 29 & 16.20 & 74 & 41.34 & 36 & 20.11 \\
\hline Ruido & 153 & 100 & 22 & 14.38 & 28 & 18.30 & 88 & 57.52 & 15 & 9.80 \\
\hline Contaminación del aire & 223 & 100 & 50 & 22.42 & 30 & 13.45 & 96 & 43.05 & 47 & 21.08 \\
\hline Problemas de salud & 114 & 100 & 21 & 18.42 & 28 & 24.56 & 43 & 37.72 & 22 & 19.30 \\
\hline Suciedad en vivienda & 159 & 100 & 33 & 20.75 & 28 & 17.61 & 71 & 44.65 & 27 & 16.98 \\
\hline
\end{tabular}

Fuente: encuesta propia.

Nota: porcentajes horizontales. Celdas en gris: porcentajes superiores al respectivo de la muestra (primera fila).

Por su parte, en el cuadro 2 es posible apreciar el grado de conciencia de los efectos en las distintas localidades. Al margen de las diferencias absolutas 
entre ellas, imputables en parte a la proporcionalidad de las submuestras, lo más revelador estriba en que, en ciertos lugares, los porcentajes de afección sentida exceden de manera, más o menos notoria, a los de la submuestra respectiva (primera fila del cuadro). Se han resaltado las celdas que exceden los valores porcentuales de la mencionada primera fila, lo que permite desvelar, como indicio, que en Horcón-Las Ventanas-La Greda y también en Loncura y Puchuncaví hay una mayor sensibilidad. La proximidad al complejo industrial apuntaría a una de las causas ese resultado, si bien esas cuestiones se abordarán más a fondo en otros análisis ulteriores.

\section{La densidad espacial de la muestra}

Como segundo punto se presentará la distribución espacial de los domicilios de los encuestados (figura 2A) y el patrón de densidad focal que conforman (figura 2B). El mapa de puntos revela una presencia de entrevistados según dos modalidades: por un lado, un reparto con cierta regularidad de ellos predominante en Quintero, Loncura y en alguna zona de los asentamientos del norte y, por otro, algunas concentraciones en partes concretas de estos últimos. En el mapa de la figura 2B se aprecia que las mayores densidades de encuestados aparecen en el ámbito de Las Ventanas-Horcón y Punchucaví. En Quintero son inferiores, aunque con un ligero aumento en su parte sur, donde en la última década se ha consolidado la zona de expansión urbana. En Loncura y La Greda se alcanzan densidades más bajas, en consonancia con el tipo de hábitat existente. Este mapa de densidad kernel de la muestra resulta importante por constituirse en la referencia para el análisis de los efectos ambientales que los residentes han percibido, los cuales, transcritos en mapas, contendrán una superficie estadística del patrón de densidad de cada efecto ambiental percibido.

En el cuadro 3 se recogen los resúmenes estadísticos de las capas raster de densidad obtenidas para los distintos efectos investigados. Ciertos estadísticos exhiben valores acordes con la frecuencia de las respuestas, por lo tanto en línea con lo esperado: así los valores máximos y las medias poseen un notable paralelismo (los mínimos no son relevantes, pues tienden siempre a cero, por efecto matemático del estimador). El coeficiente de variación, sin embargo, desvela que en tres de los efectos (olores, ruidos y polución atmosférica) las desigualdades relativas en las densidades son algo mayores que incluso las de la muestra total. Ello implicaría que espacialmente las divergencias sociales al respecto crecen, lo que podría interpretarse como una polarización relativamente mayor de las actitudes en tales casos. 
FIGURA 2

DISTRIBUCIÓN PUNTUAL (A) Y DENSIDAD NÚCLEO KERNEL (B) DE LOS ENCUESTADOS EN EL ÁREA PRÓXIMA AL COMPLEJO VENTANAS, CHILE
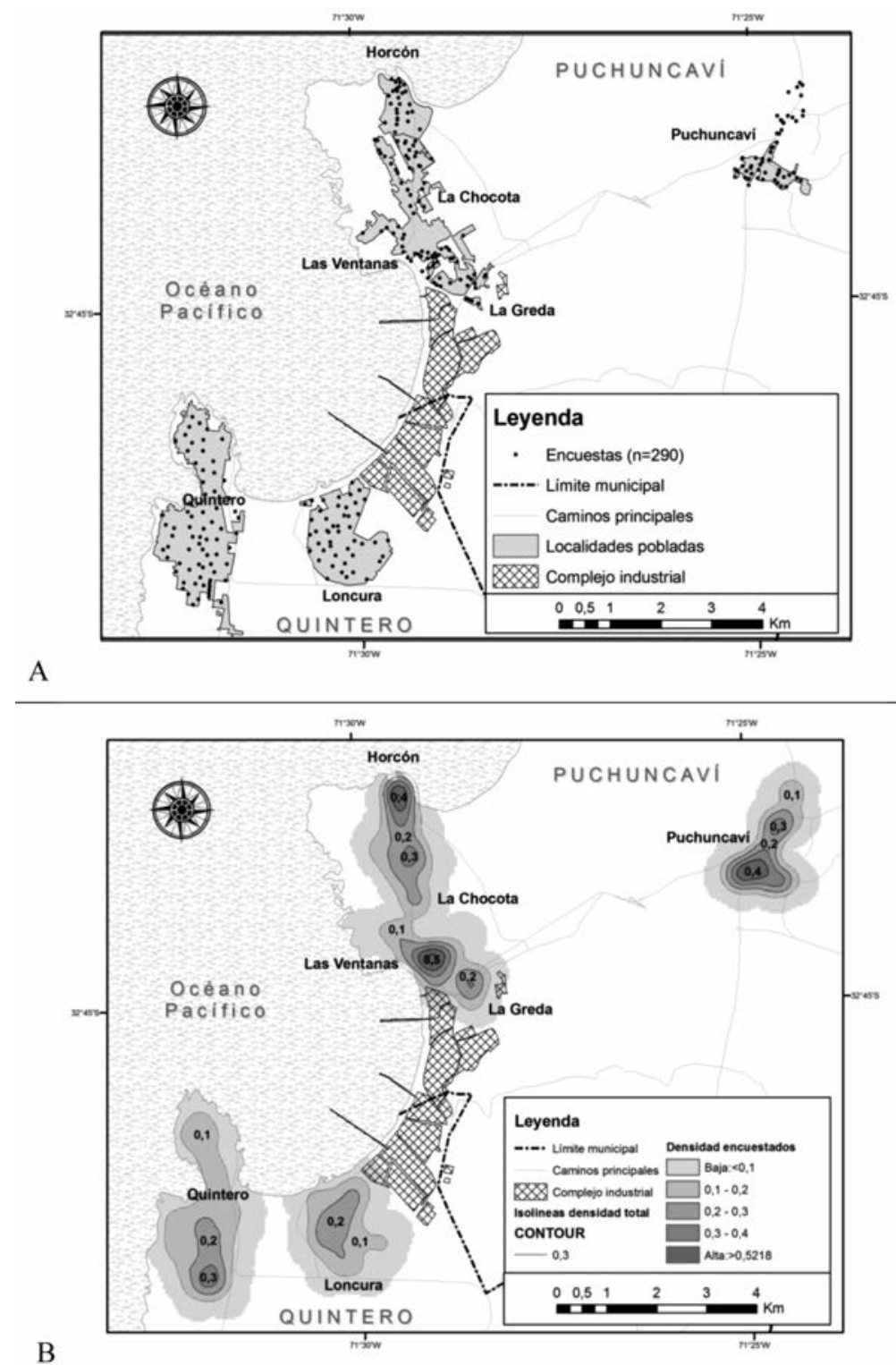

Fuente: encuesta propia.

Estudios Geográficos, Vol. LXXVIII, 282, pp. 225-256, enero-junio 2017

ISSN: 0014-1496, eISSN: 1988-8546, doi: 10.3989/estgeogr.201708 
CuAdro 3

ESTADÍSTICOS DE LAS CAPAS DE DENSIDADES KERNEL DE LOS ENCUESTADOS TOTALES Y DE LOS PERCEPTORES DE EFECTOS AMBIENTALES EN EL ENTORNO DEL COMPLEJO VENTANAS, CHILE

\begin{tabular}{l|c|c|c|c|c|c}
\hline \multirow{2}{*}{ ESTADÍSTICO } & \multirow{2}{*}{$\begin{array}{c}\text { TOTAL } \\
\text { MUESTRA }\end{array}$} & \multicolumn{5}{|c}{ TIPO DE EFECTO PERCIBIDO } \\
\cline { 5 - 8 } & & OLORES & RUIDOS & $\begin{array}{c}\text { POLUCION } \\
\text { EN AIRE }\end{array}$ & $\begin{array}{c}\text { PROBLEMAS } \\
\text { DE SALUD }\end{array}$ & $\begin{array}{c}\text { SUCIEDAD } \\
\text { EN VIVIENDA }\end{array}$ \\
\hline MEDIA & 0,112 & 0,073 & 0,068 & 0,089 & 0,052 & 0,067 \\
\hline DESVIACIÓN TÍPICA & 0,103 & 0.071 & 0,067 & 0,085 & 0,047 & 0,062 \\
\hline COEF. DE VARIACIÓN & 0,920 & 0,973 & 0,991 & 0,960 & 0,916 & 0,918 \\
\hline MÁXIMO & 0,522 & 0,396 & 0,365 & 0,474 & 0,236 & 0,326 \\
\hline MÍNIMO & 0,002 & 0,002 & 0,001 & 0,002 & 0,001 & 0,001 \\
\hline
\end{tabular}

Fuente: encuesta propia.

Nota: se han excluido de los cálculos los valores nulos. Unidades: Hab. por ha.

\section{El malestar sentido según tipos de efectos ambientales}

a) La percepción de olores

La percepción vecinal de olores (figura 3A) evidencia unas densidades mayores en las localidades Las Ventanas y Horcón (extremo N), seguidas de Puchuncaví (NE). Si bien la primera está relativamente cercana a las industrias, los otros dos asentamientos quedan más distantes. En Loncura (adyacente a la zona industrial) y Quintero el impacto resulta menos densamente percibido (solo valores bajos y medio bajos de densidad), pese a la superior proximidad al foco contaminante valorado. Estos resultados cabría relacionarlos con la dirección del viento predominante que en el periodo diurno es de suroeste, mientras que en el periodo nocturno es del este. 
FIGURA 3

DENSIDAD DEL MALESTAR SENTIDO SEGÚN TIPOS DE EFECTOS AMBIENTALES: OLORES (A) Y RUIDO (B)

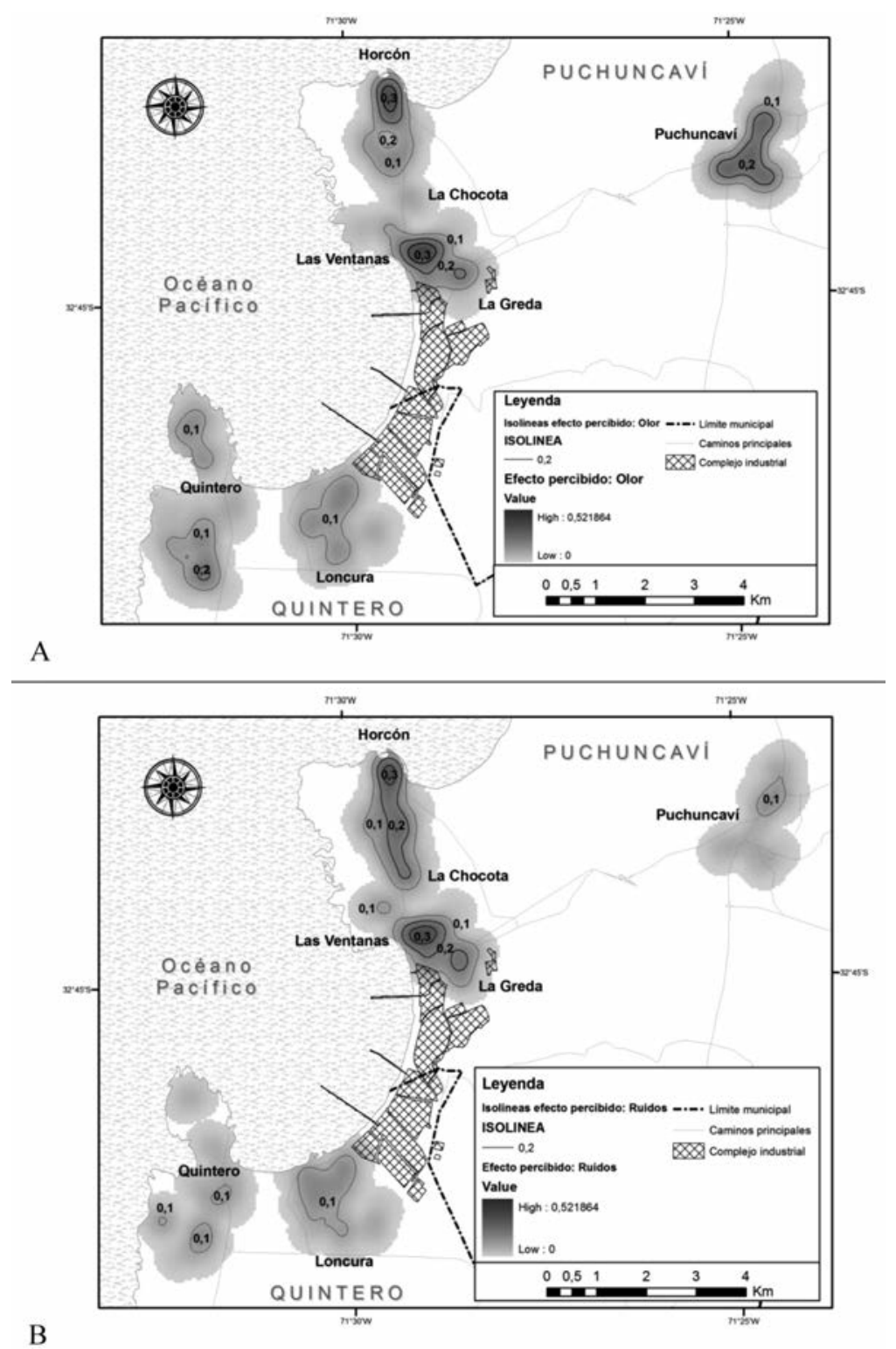

Fuente: encuesta propia.

Estudios Geográficos, Vol. LXXVIII, 282, pp. 225-256, enero-junio 2017 ISSN: 0014-1496, eISSN: 1988-8546, doi: 10.3989/estgeogr.201708 


\section{b) La percepción de ruidos}

En el caso del ruido (figura 3B) la percepción ciudadana exhibe espacialmente cambios significativos en su densidad, sobre todo cuando se la compara con la de muestra total. Aparece una mayor y amplia sensibilidad en HorcónLas Ventanas; allí el área con densidad de afectados media-alta aparece más extendida que para los olores. Ello refleja también el hecho de que la cifra de afectados (cuadro 2) sea proporcionalmente superior. Por el contrario, las densidades (y los porcentajes del cuadro 2) bajan ostensiblemente en Puchuncaví y Quintero. Recordando los factores incidentes en la difusión espacial de las ondas sonoras, entre ellos el descenso bastante rápido con la distancia: 6 dB de reducción al doblarse la distancia (Warring, 1983: 8), y el mayor alejamiento de las dos localidades mencionadas respecto al complejo fabril, resultan coherentes esas disminuciones en las apreciaciones subjetivas. En Loncura, localidad con un número de afectados proporcionalmente alto, no aparecen sin embargo concentraciones relevantes en las densidades de afección, aunque el patrón de su zona más afectada (desplazada hacia el norte) sea algo distinto al de los olores.

\section{c) La percepción de contaminación atmosférica}

La contaminación atmosférica es, como se dijo antes, el efecto más constatado por los residentes. El mapa de percepción (figura 4A) denota densidades elevadas en Horcón-Las Ventanas y Puchuncaví, con un notable paralelismo al de la distribución muestral. La afección más destacada en tales localidades (sitas al norte y noreste del complejo industrial) ha de ser puesta en relación con factores como los vientos diurnos dominantes. En Loncura y Quintero (parte sur) la extensión de la mancha de densidades medias crece también respecto a otros efectos, si bien proporcionalmente no destacan. Ambos casos se ubican al oeste de la zona industrial, lo que habrá de ser explorado con datos complementarios.

\section{d) Los problemas de salud percibidos}

La asociación entre morbilidad y emisiones industriales resulta débil en la mente de los residentes, como mostró su porcentaje medio-bajo. Ello se plasma cartográficamente en unos niveles de densidad medios y bajos en casi todas las localidades examinadas (figura 4B). Quizá el hecho más destacable 
FIGURA 4

DENSIDAD DEL MALESTAR SENTIDO SEGÚN TIPOS DE EFECTOS AMBIENTALES: POLUCIÓN DEL AIRE (A) Y PROBLEMAS DE SALUD (B)

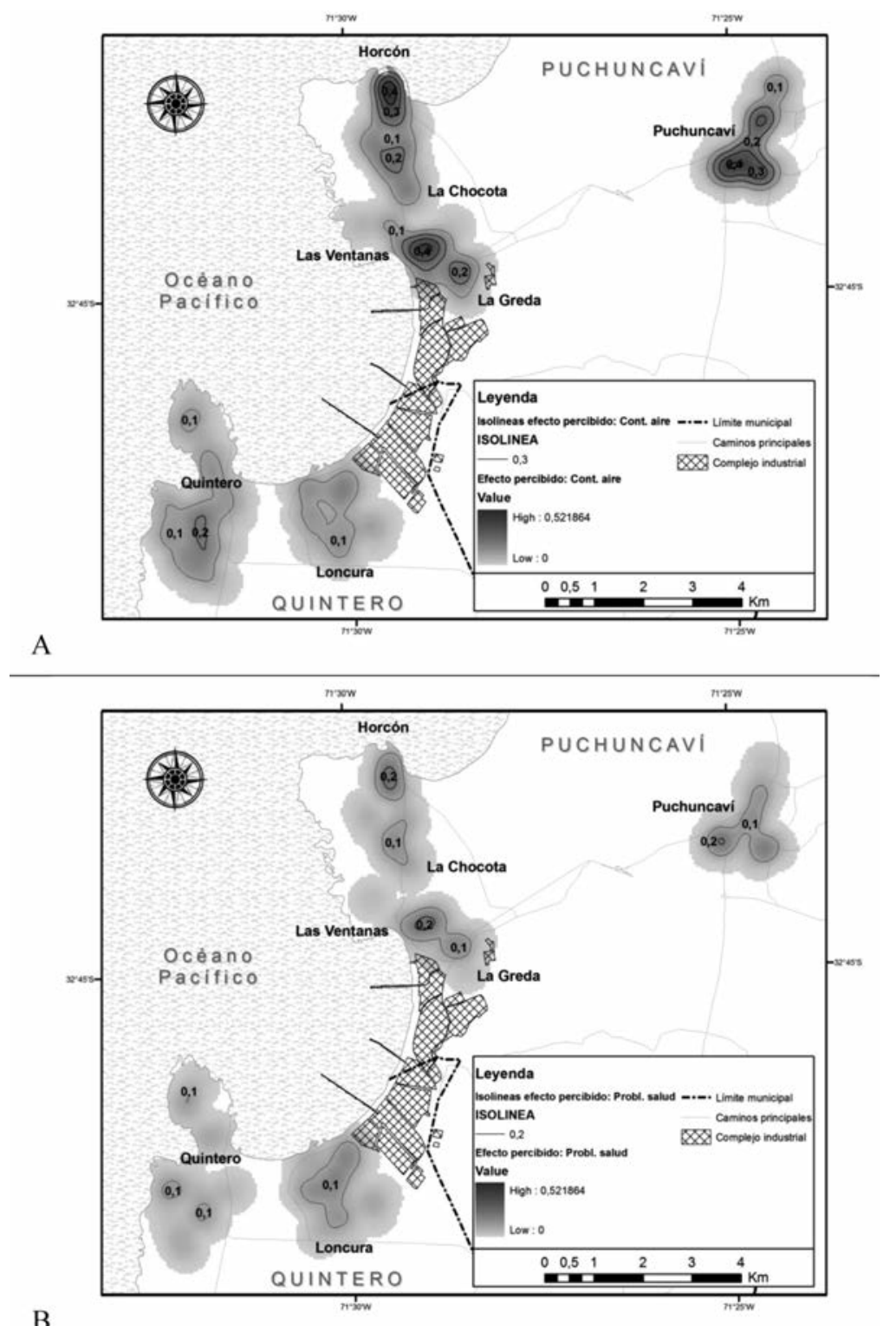

Fuente: encuesta propia.

Estudios Geográficos, Vol. LXXVIII, 282, pp. 225-256, enero-junio 2017 ISSN: 0014-1496, eISSN: 1988-8546, doi: 10.3989/estgeogr.201708 
sea la persistente extensión de la zona de densidad media en Loncura. Esto puede relacionarse con su contigüidad al complejo industrial y con la existencia de una cifra de afectados proporcionalmente superior, tal como se evidenció en el cuadro $\mathrm{N}^{\circ} 2$.

\section{e) La suciedad en viviendas}

Este efecto, sentido por algo más de la mitad de los encuestados, se manifiesta proporcionalmente más solo en Horcón-La Ventanas, siendo la densidad mayor en la zona concreta de La Greda, adyacente al complejo (figura 5). En los restantes lugares las densidades predominantes son medio-bajas y bajas.

FIGURA 5

\section{DENSIDAD DEL MALESTAR SENTIDO SEGÚN TIPOS DE EFECTOS AMBIENTALES: SUCIEDAD EN VIVIENDAS}

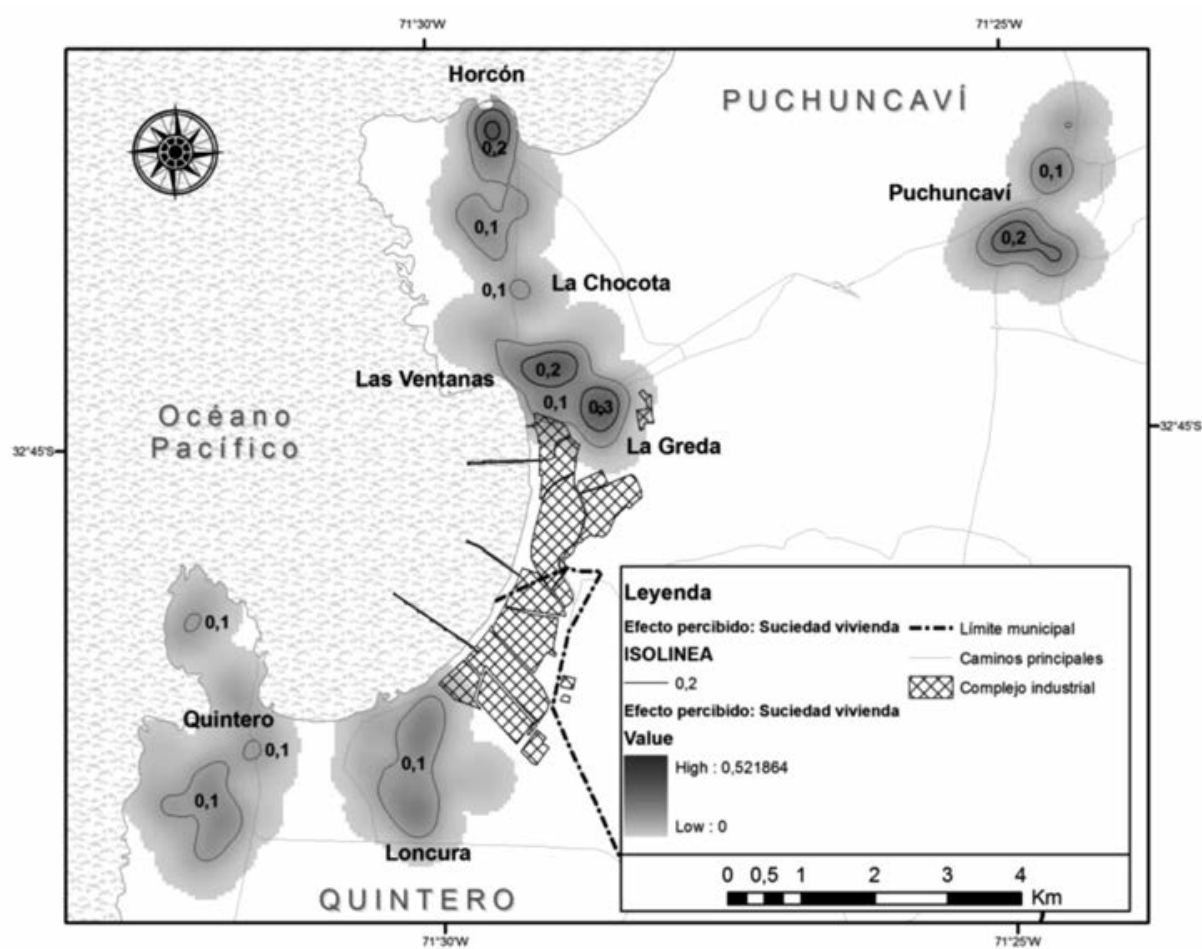

Fuente: encuesta propia. 
f) Hacia un diagnóstico sintético: el indicador de multi-afección ambiental percibida (IMAP)

El último mapa elaborado (figura 6) intenta resumir mediante un índice de forma aditiva las respuestas a las cinco preguntas directas sobre la percepción social de los problemas ambientales, elaborado según se describió en el apartado de técnicas de análisis. En conjunto, niveles medio-altos solo afloran en algunas zonas pequeñas de Horcón-Las Ventanas sitas al norte y un poco en el sur de Puchuncaví. En éste asentamiento prevalecen las densidades bajas y medio-bajas de afectados, siendo esa la tónica ahora también de Loncura y Quintero. En el primero de ellos la zona con densidad medio-baja sigue exhibiendo una extensión muy notable respecto al área del asentamiento, rasgo que ha persistido a lo largo de los mapas expuestos.

FIGURA 6

DENSIDAD DEL MALESTAR SENTIDO: ÍNDICE DE MULTIAFECCIÓN AMBIENTAL PERCIBIDA

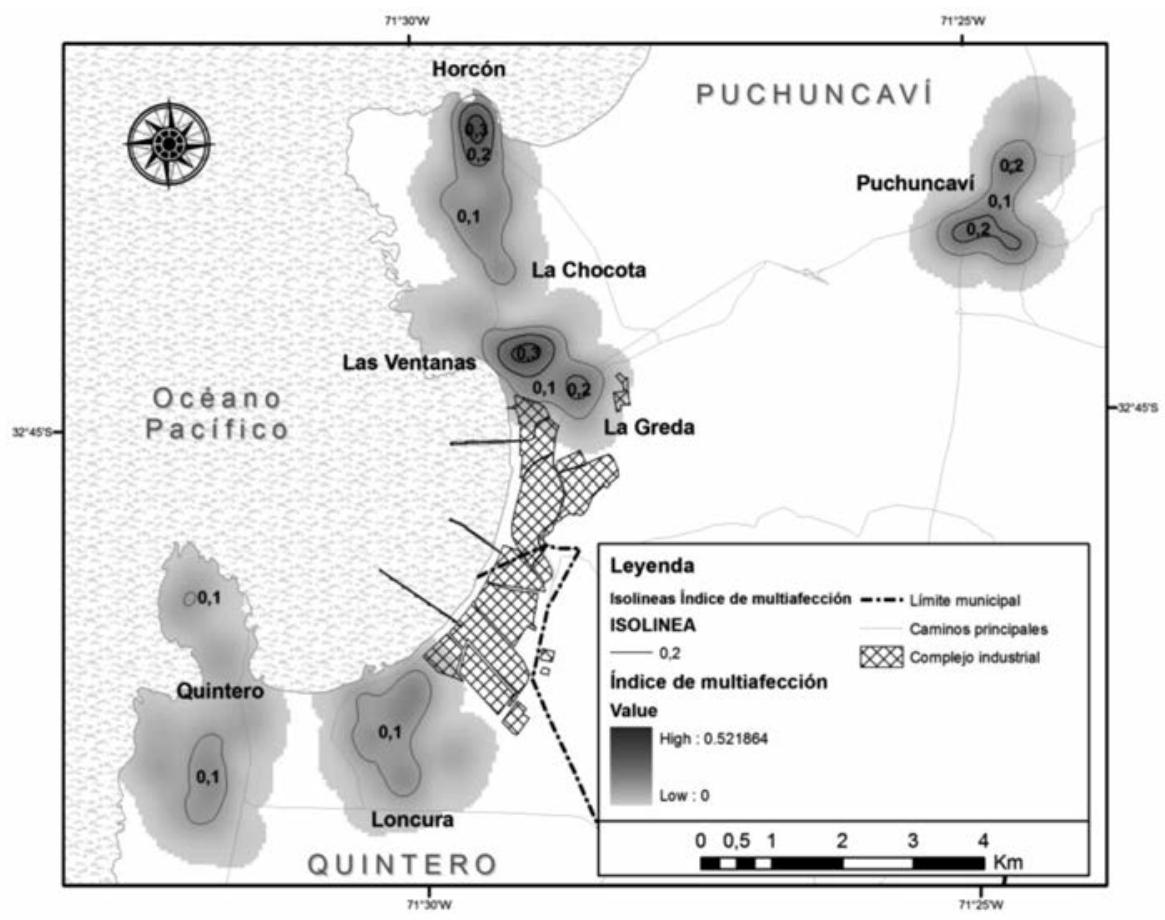

Fuente: encuesta propia.

Estudios Geográficos, Vol. LXXVIII, 282, pp. 225-256, enero-junio 2017

ISSN: 0014-1496, eISSN: 1988-8546, doi: 10.3989/estgeogr.201708 


\section{DISCUSIÓN}

Partiendo de la preocupación por los impactos ambientales de ciertas actividades, en este trabajo el centro de atención se ha puesto en la obtención de información de naturaleza subjetiva mediante encuestas a los residentes en ámbitos de potencial afección, por su cercanía a la fuente del deterioro ambiental, y en la cartografía de la misma. En esa dirección, varios autores han apostado por analizar y representar la afección mediante tipos de mapas conceptualmente distintos, cuyas utilidades resultan también correlativamente desiguales. Así por ejemplo, en algunos casos, e. g. Sofer et al. (2012) y en este trabajo, el acento se ha puesto en obtener resúmenes estadísticos de la afección por unidades espaciales (e. g. asentamientos) lo que simplifica el mensaje, a costa de perder el detalle espacial, puesto que las zonas pueden resultar grandes, inapropiadas en geometría o vagamente definidas (el problema de la unidad espacial modificable). En otros casos, el objetivo ha recaído en determinar campos de externalidades subjetivas a partir de una apreciación de la intensidad del efecto percibido mediante una escala ordinal (Bale, 1981, 1990; Mason y Robins, 1991; Mason y Moncrieff, 1993; Chase y Healey, 1995). Esto último posibilita plasmar en mapas de isopletas dicha intensidad. Su significado sería equivalente al de los niveles de inmisión estimados para contaminantes atmosféricos, un resultado de indudable significación, si bien tales mapas no reflejan, ni permiten conocer la densidad / magnitud del malestar social en cada lugar, pues esta depende de la distribución territorial del universo y de la representatividad espacial muestra. La aproximación realizada por Bonnet et al. $(2012,2014)$ para delimitar zonas de riesgo se sustenta en el conocimiento o apreciación territorial, i.e. el mapa mental de los encuestados. Dado que la identificación de los ámbitos con impactos sentidos se sustenta en conjeturas o estimaciones -a partir de la localización residencial de las personas entrevistadas y de sus campos de información y de actividad- esa información evidenció desigualdades en las superficies estimadas de riesgo y una subestimación respecto a las cartografías oficiales, según reconocen dichos autores, por lo que la cartografía derivada puede adolecer de importantes debilidades y resultar errónea.

En nuestro estudio, el foco principal ha recaído en intentar obtener una cartografía a) reveladora de la magnitud de los efectos ambientales sentidos, que se aproximaría en su significado a una contabilidad socio-espacial, es decir, se ha tratado de mostrar cuánta cantidad de gente se siente afectada en cada lugar, considerando la masa demográfica afectable; y b) sustentada en una desagregación espacial elevada y estandarizada, que facilite la interpreta- 
ción y la comparación. Ello se ha instrumentado mediante decisiones metodológicas y requisitos que conviene subrayar.

Si la muestra de encuestados se seleccionó espacialmente de forma representativa, en el sentido de ser similar y proporcional a la distribución espacial del universo (i.e. su densidad), entonces un diseño muestra tal, como aquí se ha realizado, permite ser entendido como un retrato territorial de los efectos percibidos en cada lugar. En tal caso, las respuestas contienen, además del nivel de molestia (si se averiguó en la encuesta), un primer significado cuantitativo obvio: la cifra total de los afectados reflejaría la magnitud del impacto negativo absoluto, lo que sería asimilable al malestar total recogido en la muestra. Por otro lado, la localización de los domicilios de los encuestados, aparte de la información temática sobre la percepción, contiene un valor adicional, en tanto que representación del micro-entorno donde vive la persona.

La simple trasposición espacial de los datos de las entrevistas como puntos (e.g. el domicilio) resulta algo reduccionista, por cuanto esa percepción cabe presumirla referida, más atinadamente, a un campo de actividad e información del individuo que, centrado en su domicilio, involucra al área circundante al mismo. Es ahí donde una segunda decisión metodológica, la manera de plasmar geográficamente los resultados, ha intentado añadir un plusvalor respecto a otros trabajos. A diferencia de estudios previos que eluden tal aspecto, en el presente trabajo se ha priorizado la «espacialización» de ese malestar total. Al respecto, frente a la alternativa habitual de resumir los hallazgos por localidades o áreas de límites discutibles, aquí se ha propuesto una aproximación muy desagregada espacialmente. Se basa en la metodología planteada por Moreno (1992 y 1998) que persigue dar una visión más precisa de los impactos socio-ambientales allí donde ocurren, es decir, se trata de desvelar la distribución espacial del malestar social subjetivo imputable a las externalidades ambientales generadas por el complejo industrial. A tal fin, partiendo de una referenciación puntual de los encuestados en el territorio (su domicilio), resulta apropiado usar un procedimiento como el estimador núcleo (kernel) para plasmar la afección de forma espacialmente detallada. Procede recordar que, por la estructura matemática de las funciones de densidad kernel, el valor unitario de cada afectado se reparte (según el tipo de kernel) entre los píxeles del entorno del punto-domicilio de manera descendente con la distancia. De ese modo, el micro-entorno de un encuestado «afectado» quedaría teñido también como impactado. Al mismo tiempo se mantiene la propiedad de que la cuantía (volumen) bajo la superficie de densidad es equivalente a la frecuencia de los puntos, es decir, a la cantidad 
de afectados y a lo que representan, el malestar total capturado por la muestra. En resumen, la capa raster de densidad de afección en la muestra exhibiría un patrón representativo de la densidad de afección en el universo, lo cual a nuestro juicio constituye un avance en la evaluación de los impactos ambientales. Como es sabido, las propiedades de dichas capas hacen posible no solo su examen visual y la consulta de los valores de densidad interactivamente, sino también otras operaciones con SIG para analizar espacialmente esas distribuciones y explorar relaciones con otras variables, cuestiones que aquí no se han abordado.

Desde el punto de vista empírico, esta investigación ha permitido conocer una variedad de patrones de malestar socio-espacial subjetivo asociados a un gran complejo industrial. En ellos han aparecido diferencias espaciales vinculables, por un lado, a las propias densidades espaciales de la muestra (proporcionales a la del universo), lo cual refleja obviamente que la mayor concentración de residentes tiende a ocasionar concentraciones de malestar, aunque no siempre en una cuantía proporcional; por otro, se han detectado variaciones que podrían estar relacionadas con la distancia al complejo industrial o con la posición relativa (orientación), probablemente, como consecuencia de la forma de dispersión de los contaminantes. Algunos de estos hallazgos tienen cierta analogía con los descritos en Moreno (1998), Sofer et al. (2012) y los estudios mencionados antes sobre campos de externalidades de ciertos equipamientos. En todo caso, relaciones como las recién mencionadas no han sido objeto de examen sistemático aquí y se abordarán en ulteriores análisis. Igualmente, otras cuestiones atingentes a los correlatos de las respuestas con los atributos personales o su asociación con algunos indicadores objetivos (mediciones de las inmisiones contaminantes con instrumentos ad hoc), para fines explicativos y de evaluación quedan pendientes de explorar.

\section{Conclusiones}

La existencia de entornos de baja calidad ambiental derivados de fenómenos naturales, actividades nocivas y peligrosas, conductas sociales molestas, etc. ha dado lugar a una sugestiva tradición de estudios y a regulaciones crecientes sobre los impactos que ocasionan a la población. Los enfoques adoptados en tales análisis han sido variados, debido a la pluralidad de manifestaciones de esos efectos y a la diversidad de los objetivos avistados.

Dejando a un lado las indagaciones que han buscado bien determinar ex ante las zonas potencialmente impactadas (basándose p. ej. en datos de emi- 
siones-inmisiones o en criterios de proximidad), o bien explicar ex - post esos efectos, por no haber sido objeto de atención en nuestro trabajo, la dirección centrada en la caracterización y aprehensión exacta de los efectos ocasionados presenta aún aspectos metodológicos pendientes de mejorar y contrastar. Junto a los también imprescindibles indicadores objetivos de impactos sociales, por ejemplo, los de morbilidad / mortalidad vinculados a factores ambientales, un cierto número de estudios ha priorizado como base informativa las percepciones y sensaciones de la población, como vía para conocer mejor el malestar-bienestar que existe en aquellos lugares donde se constata un ambiente degradado. En comparación con los ensayos de otros autores, nuestro trabajo ha aportado un planteamiento y una solución metodológica distintos al reto de cuantificar, de forma espacialmente detallada, la magnitud de ese malestar y mostrarla mediante el recurso a un tipo de muestreo espacial y a una técnica de representación, las densidades focales núcleo (kernel) que desembocan en mapas eficaces e idóneos para ese fin. De ese modo, unos datos muestrales espacialmente representativos de la densidad del universo y georreferenciados como puntos pueden ser técnicamente traspuestos a valores en capas raster de densidad de afectados, que constituyen una estimación aproximada de la cantidad de malestar sentido en cada lugar (y con la resolución espacial que se desee). Su visualización posibilita una aprehensión espacialmente pormenorizada y más exacta que la lograda mediante los tradicionales recuentos por áreas administrativas.

Desde el punto de vista de su aplicación cabe proponer su utilidad para identificar y localizar la magnitud de la conflictividad latente y, de manera más general, a la hora de caracterizar situaciones territoriales desde principios como los de calidad de vida, bienestar, justicia ambiental o sostenibilidad. Tales diagnósticos serían pertinentes luego en los procesos de ordenación espacial sensu lato y en el dimensionamiento y gestión de costes indirectos de actividades molestas, insalubres, nocivas o peligrosas.

Finalmente, aunque los patrones de afección presentados aquí para la zona de estudio han servido para desvelar ya unas realidades ocultas hasta ahora, pero de interés prioritario, procede reconocer que un análisis más profundo de las mismas y de las relaciones con otras variables (factores determinantes) queda por hacer y se acometerá próximamente, con la intención de identificar bases explicativas e interpretativas de esos fenómenos. En esa línea, las aportaciones expuestas brevemente en el apartado de antecedentes de estudio, con sus hallazgos y limitaciones, habrán de dar marco de referencia. 
BIBLIOGRAFÍA

Arteaga, M. y Pasquali, C. (2013): "Impacto socio-ambiental de las empresas cárnicas de los Valles del Tuy: percepción comunitaria", Multiciencias, 13/4, pp. 363-371.

Bale, J. (1981): "Teaching welfare issues in Geography", en R. Walford (ed.) Signposts for geography teaching, Londres, Longman, pp. 51-63.

Bale, J. (1990): "In the shadow of the stadium: football grounds as urban nuisances", Geography, 75, pp. 325-344.

Barroto, M., Rodríguez, L., Reyes, A. y López, B. (2011): "Percepción ambiental en dos comunidades cubanas", M+A Revista electrónica de Medio Ambiente, 10, pp. 13-29. http://dx.doi.org/10.5209/rev_MARE.2011.n10.15854 (fecha de consulta: 19/2/2016).

Baxter, J. y Greenlaw, K. (2005): "Explaining perceptions of a technological environmental hazard using comparative analysis", Canadian Geographer, 49/1, pp. 61-80.

Bickerstaff, K. (2004): "Risk perception research: socio-cultural perspectives on the public experience of air pollution", Environment International, 30/6, pp. 827-840.

Bonnet, E., Amalric, M. y Cheve, M. (2014): "Mapping mental representations of industrial risk: illustrated with the populations of the Estuary of the Seine River, France", Cartographica, 49/2, pp. 102-113.

Bonnet, E., Amalric, M., Cheve, M. y Travers, M. (2012): "Hazard and living environment: Combining industrial risk and landscape representations", Journal of Risk Research, 15/10, pp. 1281-98.

Brody, S. D., Peck, B. M. y Highfield, W. E. (2004): "Examining localized patterns of air quality perception in Texas: A spatial and statistical analysis", Risk Analysis, 24/6, pp. 1561-1574.

Buzai, G. D. (2011a): "La geotecnología: ¿Nuevo paradigma de la geografía o paradigma geográfico de la ciencia?", Revista Catalana de Geografía, XVI/42, www.rcg.cat/articles.php?id=187 (fecha de consulta: 19/2/2016).

Buzai, G. D. (2011b): "La construcción de mapas mentales mediante apoyo geoinformático. Desde las imágenes mentales perceptivas hacia la modelización digital", Revista Geográfica de Valparaíso, 44, pp. 1-17.

Castro Aguirre, C. de (2004): Mapas mentales, Pamplona, Servicio de Publicaciones de la Universidad Pública de Navarra, 248 pp.

Catalán-Vázquez, M. y Jarillo-Soto, E. (2010): "Paradigmas de investigación aplicados al estudio de la percepción pública de la contaminación del aire", Revista Internacional de Contaminación Industrial, 26/2, pp. 165-178.

Catling, S. J. (1978): "Cognitive mapping exercises as a primary geographical experience", Teaching Geography, 3, pp. 120-123.

Chase, J. y Healey, M. (1995): "The spatial externality effects of football matches and rock concerts - The case of Portman Road Stadium, Ipswich, Suffolk", Applied Geography, 15/1, pp. 18-34.

Dear, M., Taylor, S. M. y Hall, G. B. (1980): "External effects of mental health facilities", Annals of the Association of American Geographers, 70/3, pp. 342-352. 
Fischhoff, B., Slovic, P., Lichtenstein, S., Read, S. y Combs, B. (1978): "How safe is safe enough? A psychometric study of attitudes towards technological risks and benefits", Policy Science, 9, pp. 127-152.

Ford, S., Moore, J., Niswonger, J. y Walsh, E. (2007): "GIS technical report: Spatial distribution of industrial land use and children's perception of safety and their environment", The University of Texas at Austin, pdf Report.

Glatron, S. y Beck, E. (2005): "Prévention des risques majeurs dans l'agglomération mulhousienne: quelles perceptions et quels points de vue des actions?", Les Cahiers de l'IAURIF, 142, pp. 105-117.

Glatron, S. y Beck, E. (2008): "Evaluation of socio-spatial vulnerability of citydwellers and analysis of risk perception: industrial and seismic risks in Mulhouse", Natural Hazards and Earth System Sciences, 8, pp. 1029-1040.

Golledge, R. y Stimpson, R. (1997): Spatial behavior. A geographic perspective, New York, The Guilford Press.

Gould, P. y White, R. (1974): Mental maps, Londres, Penguin.

Gould, P. (1975): "People in information space: The mental maps and information surface of Sweden", Lund Studies in Geography, Ser. B Human Geography, 42.

Gould, P. y White, R. (1974): Mental maps, Londres, Penguin.

Gutteling, J. y Wiegman, O. (1993): "Gender-specific reactions to environmental hazards in the Netherlands", Sex Roles, 28/7/8, pp. 433-447.

Hintze, J. (2013): NCSS 9, Kaysville (Utah, USA), NCSS, LLC, www.ncss.com.

Jiménez Burillo, F. y Aragonés, J. I. (1991): Introducción a la psicología ambiental, Madrid, Alianza Editorial.

Keown, C. F. (1989): "Risk perceptions of Hong Kongese vs. Americans", Risk Analysis, 9, pp. 401-405.

Kleinhesselink, R. R. y Rosa, E. A. (1991): “Cognitive representation of risk perceptions: A comparison of Japan and the United States", Journal of Cross-Cultural Psychology, 22, pp. 11-28.

Lai, J. C. y Tao, J. (2003): "Perception of environmental hazards in Hong Kong Chinese", Risk Analysis, 23/4, pp. 669-684

Lynch, K. (1960): The image of the city, Massachusetts, MIT Press, Cambridge.

Mason, C. y Moncrieff, A. (1993): "The effect of relocation on the externality fields of football stadia: The case of St Johnstone FC", Scottish Geographical Magazine, 109/2, pp. 96-105.

Mason, C. y Robins, R. (1991): "The spatial externality fields of football stadiums: the effects of football and non-football uses at Kenilworth Road, Luton", Applied Geography, 11/4, pp. 251-266.

Moreno Jiménez, A. (1991): "Modelización cartográfica de densidades mediante estimadores kernel", Treballs de la Societat Catalana de Geografía, 30, pp. 155-170. http://www.raco.cat/index.php/TreballsSCGeografia/article/view/184519/237797 (fecha de consulta: 19/2/2016).

Moreno Jiménez, A. (1992): "Spatial impact analysis and site selection for controver- 
sial public facilities with GIS", EGIS'92, Third European Conference and Exhibition on Geographical Information Systems, Utrecht, EGIS Foundation, 1, pp. 483-491.

Moreno Jiménez, A. (1998): "Los mapas de actitudes hacia el entorno: un instrumento para la exploración del espacio psico-social y la toma de decisiones con S.I.G.” en P. Alegre (coord.), Tecnología geográfica para el siglo XXI, VIII Coloquio de Geografía Cuantitativa, Barcelona, Universidad Autónoma de Barcelona, pp. 247-263, http://www.age-geografia.es/tig/barcelona98/1998_018_moreno.pdf (fecha de consulta: 19/2/2017).

Moreno Jiménez, A. (2010): "GeoFocus: diez años en el camino hacia la sociedad de la geoinformación”, GeoFocus (ed.), 10, pp. 1-6. www.geofocus.org/index.php/geofocus/article/view/188/44 (fecha de consulta: 19/2/2017).

Moreno Jiménez, A. (2013): "Entendimiento y naturaleza de la cientificidad geotecnológica: una aproximación desde el pragmatismo epistemológico", Investigaciones Geográficas, 60, pp. 5-36. http://rua.ua.es/dspace/bitstream/10045/34742/1/ Investigaciones_Geograficas_60_01.pdf (fecha de consulta: 19/2/2016).

Moreno Jiménez, A. y Escolano Utrilla, S. (1992): El comercio y los servicios para la producción y el consumo, Madrid, Editorial Síntesis.

Pérez-Tejera, F. (2012): "Diferencias entre los usuarios de seis parques públicos en Barcelona según el nivel de seguridad percibida en el barrio", Athenea Digital, 12/1, pp. 55-66.

Pinch, S. (1985): Cities and services. The geography of collective consumption, Londres, Routledge and Kegan Paul.

Propeck-Zimmermann E., Saint-Gerand T. y Bonnet E. (2009) : "Nouvelles approches ergonomiques de la cartographie des risques industriels", Mappemonde, 96/4, 19 pp. http://mappemonde.mgm.fr/num24/articles/art09402.html (fecha de consulta: 19/2/2016).

Santos Preciado, J. M. y García Lázaro, F. J. (2008): Análisis estadístico de la información geográfica, Madrid, UNED.

Schroeder, H. (1984): "Environmental perception rating scales. A case for simple methods analysis", Environment and Behavior, 16/5, pp. 573-598.

Shippee, G., Burroughs, J. y Wakefield, S. (1980): "Dissonance theory revisited: Perception of environmental hazards in residential areas", Environment and Behavior, 12/1, pp. 33-51.

Siegrist, M., Keller, C. y Kiers, H. A. L. (2005): "A new look at the psychometric paradigm of perception of hazards", Risk Analysis, 25/1, pp. 211-222.

Silverman, B. W. (1986): Density estimation for statistics and data analysis, New York, Chapman and Hall.

Sofer, M., Potchter, O., Gnaim, N. y Gnaim, J. (2012): "Environmental nuisances from industrial activities in residential areas of Arab municipalities in Israel", Applied Geography, 35, pp. 353-362.

Stefanko, M. y Horowitz, J. (1989): "Attitudinal effects associated with an environmental hazard", Population and Environment, 11/1, pp. 43-57. 
Valera, S., Pol, E. y Vidal, T. (s.f.): "Elementos básicos de psicología ambiental”, Barcelona, Universitat de Barcelona.

Warring, R. (1983): Handbook of noise and vibration control, Morden, Trade and Technical Press, $5^{\mathrm{a}}$ ed.

Zhang, Y., Hwang, S. N. y Lindell, M. K. (2010): "Hazard proximity or risk perception? Evaluating effects of natural and technological hazards on housing values", Environment and Behavior, 42/5, pp. 597-624.

Fecha de recepción: 29 de junio de 2015.

Fecha de aceptación: 11 de abril de 2016. 